\title{
Effect of post curing method on flexural strength of composite friction brake
}

\author{
Herru Santoso Budiono ${ }^{1}$, Eko Surojo ${ }^{2}$, Nurul Muhayat ${ }^{2}$, and Wijang Wisnu Raharjo ${ }^{2}$ \\ ${ }^{1}$ Graduate school of Mechanical Engineering, Universitas Sebelas Maret, Surakarta, Indonesia \\ ${ }^{2}$ Department of Mechanical Engineering, Faculty of Engineering, Universitas Sebelas Maret, Surakarta, \\ Indonesia
}

\begin{abstract}
Friction brake material is important component in the braking system of the vehicles. These materials are usually made of asbestos and non-asbestos materials. Some non-asbestos materials use natural fibers as reinforcement and phenolic resin as a binder. The post-curing process is carried out by heating a material with specific temperature and time. During post curing, ammonia gas as the reaction of the phenolic resin and HMTA diffuses out from the friction brake material. The heating rate in post curing was supposed affecting process of removal ammonia gas from composite and it will affect mechanical properties of the composite. Therefore, this paper is concerned with effect of post curing method on the composite flexural strength. Composite specimen were manufactured by mixing the ingredients, preforming, hot molding and followed by post curing. Bending tests performed to determine the effect of post curing the flexural strength. The results showed that heating rate in post curing affected flexural strength of composite. Flexural strength of composite decreased with increasing heating rate. Internal defect that were formed during post curing decreased composite flexural strength.
\end{abstract}

\section{Introduction}

The friction brake is important components in the braking system for all kinds of vehicles [1]. Friction brake on the braking system is used to control the speed by converting kinetic energy into frictional energy [2]. The friction brake should have the coefficient of friction as required, high wear resistance, and high stability in coefficient of friction [3]. To fulfill of these characteristics can not be obtained using one type of material and is only possible by combining multiple materials [4]. Composite materials for friction brake is composed by many materials. The ingredients that used in the composite brake affect its characteristics. Therefore, the selection of materials in the manufacture of composite friction brake needs to be done [5]. Phenolic resin is usually used as a binder in the manufacture of the friction brake.

Phenolic resin is fire resistant resin that is superior compared to other types of fireresistant resin [6]. The material is often used in the industry because of its resistance at high temperatures and its good performance [7]. Those characteristics were produce by crosslinking network structure in the form of three-dimensional arising from the post-curing process of the resin novolac with hexamethylenetetramine (HMTA). The reaction between 
the phenolic resin and HMTA also generates ammonia gas [8]. The ammonia gas can be removed with a post-curing process [9].

In addition to eliminate the ammonia gas, post curing also increases the density of cross-links in the network phenolic resin [10]. Increasing of cross-link will increase its temperature glass ( $\mathrm{Tg}$ ) [11]. By varying the time, this kind of catalyst, and the ratio of formaldehyde, some characteristics can be produced [12]. The release of gas from composite materials through the diffusion mechanism. Several previous studies have studied effects of post curing on physical and tribological properties. Post curing has an effect on storage modulus [11]. The best wear resistant and friction stability obtain at 6 hours with a temperature of $200^{\circ} \mathrm{C}$ [13]. Almost of all of those researches were just concerned about physical properties and tribological behaviours. Therefore, this work focused to investigate effect of post curing method on composite flexural strength. Particular attention was directed to changes in flexural strength with respect to variation of heating rate and duration

\section{Materials and Methodology}

In this study, the composition of the materials used was: fly ash (4.24\%), $\mathrm{CaCO} 3(40.48 \%)$, NBR $(2.77 \%)$, Graphite $(30.68 \%)$, cashew (3.47\%), cantula fiber $(2.56 \%)$ and phenolic resin $(15.79 \%)$. Before mixing, cantula fibers was alkali treated to remove the lignin content. Alkali treatment process was carried out by soaking the fiber using $5 \% \mathrm{NaOH}$ solution and distilled water for 4 hours and then heated in the oven with a temperature of $70^{\circ} \mathrm{C}$ for 10 hours. After the alkali treated, cantula fibers cut to a length of $3 \mathrm{~mm}$.

The bending test specimen was manufactured by a sequence of process as follows : dry mixing of the ingredients, cold molding, hot molding, and then followed by post curing. The temperatures used in the hot molding process was $160^{\circ} \mathrm{C}$ for 10 minutes at a pressure of $20 \mathrm{MPa}$. Bending test was performed by using ASTM standard D790 (three-point bending test) of the size as shown in Fig. 1.

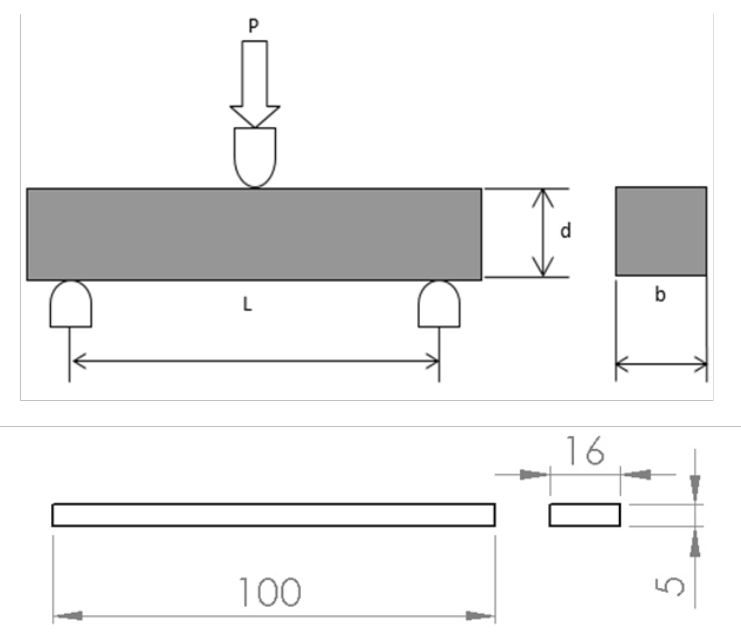

(a)

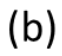

Fig. 1. (a) three-point bending test ASTM D790, (b) Size bending test specimen (mm)

Post curing was carried out by three step of heat treatment. The first step, specimens were continuous heated from room temperature to $140^{\circ} \mathrm{C}$ in 1 hour. The second step, 
specimens were heated using method as shown in Table 1. The third step, specimens were slowly cooled from $180^{\circ} \mathrm{C}$ to room temperature in the oven.

Table 1. Variations of the second step of post curing

\begin{tabular}{|l|l|}
\hline $\begin{array}{c}\text { Heating } \\
\text { method }\end{array}$ & Variation \\
\hline $\begin{array}{l}\text { Continuous } \\
\text { heating }\end{array}$ & Specimens were slowly heated from $140^{\circ} \mathrm{C}$ to $180^{\circ} \mathrm{C}$ in $: 2,4,6$, and 8 hours \\
\hline $\begin{array}{l}\text { Isothermal } \\
\text { heating }\end{array}$ & $\begin{array}{l}\text { Specimens were rapidly heated from } 140^{\circ} \mathrm{C} \text { to } 180^{\circ} \mathrm{C} \text { in } 5 \text { minutes and then } \\
\text { held at } 180^{\circ} \mathrm{C} \text { for }: 2,4,6, \text { and } 8 \text { hours }\end{array}$ \\
\hline
\end{tabular}

\section{Result and discussion}

The result of bending test is shown in Fig. 2. The specimen of bending test by the continuous heating method with 2 hours of heating rate had an average flexural strength of $26 \mathrm{MPa}$. The flexural strength of the specimen increased when the heating time was increased from 2 hours to 4 hours and to 6 hours. Meanwhile, the flexural strength did not increased when the heating time was increased from 6 hours to 8 hours. In the continuous heating method, it was found that there was a correlation between the heating duration and the heating rate. The heating rate from $140^{\circ} \mathrm{C}$ to $180^{\circ} \mathrm{C}$ decreased as the heating time increased. The specimen with 2 hours and 4 hours of heating time underwent the post curing in heating rate of $(180-140) / 2{ }^{\circ} \mathrm{C} /$ hour and $(180-140) / 4{ }^{\circ} \mathrm{C} /$ hour, respectively.

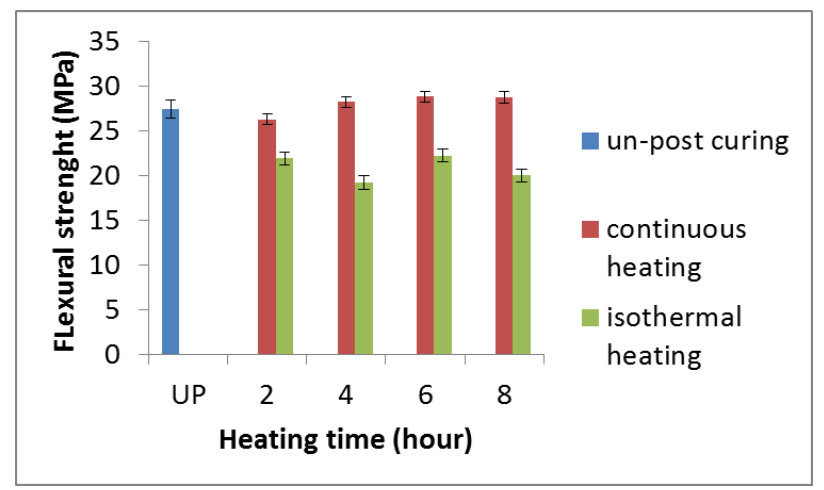

Fig. 2. Effect post curing method on friction brake material (UP = un-post curing)

For each similar heating time, the applied isothermal heating method resulted in a lower flexural strength compared to that of continuous heating. Eventhough the heating time variation was similar, the heating rate in isothermal heating was faster than that found in continuous heating. All specimens that underwent isothermal heating method were heated from $140^{\circ} \mathrm{C}$ to $180^{\circ} \mathrm{C}$ with same heating rate i.e $(180-140) /(5 / 60){ }^{\circ} \mathrm{C} /$ hour. Therefore, Fig. 2 indicated that heating rate influence the flexural strength of the composite. Flexural strength tended to decrease as the heating rate increased. Optimal flexural strength was 
reached in the specimen that underwent continuous heating treatment in 6 hours. Meanwhile, the specimen that underwent continuous heating treatment for 2 hours had lower flexural strength compared to that which was unpost-cured.

The influence of heating rate on the composite flexural strength was related to the formation of internal defects during the post curing process. Fig. 3 shows the existence of internal defect that supports the hypothesis. The specimen which underwent treatment using continuous heating method in 2 hours of heating time showed internal defect (Fig. 3a), while that in 6 hours of heating time showed no internal defect (Fig. 3b). The specimen which underwent treatment using isothermal heating method with 2 hours of heating time had a greater internal defect than that which underwent continuous heating with 2 hours of heating time (Fig. 3c). There was a possible reason why that phenomenon occurred. The internal defect occurred as the result of ammonia gas which was formed and trapped in the specimen during post curing. It revealed that the heating rate affected the release process of ammonia gas from composite. Increasing of heating rate tended to induce formation of internal defect in composite. The un-post cured specimen did not have any internal defects (Fig. 3d) as found in the continuous heating specimen and in the isothermal heating specimen.

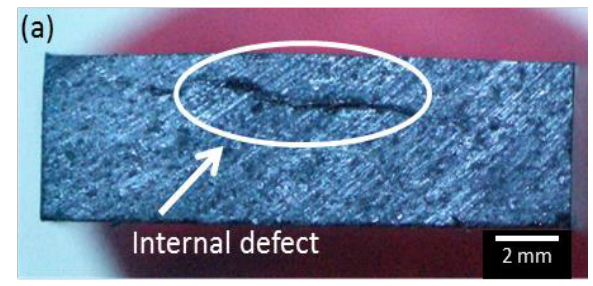

(c)

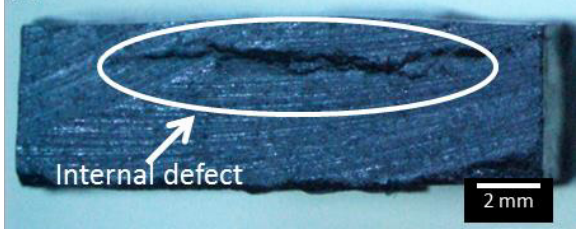

(b)

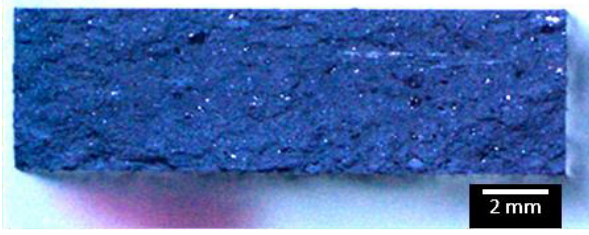

(d)

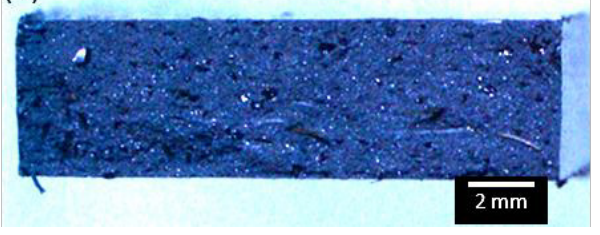

Fig. 3. Fracture surface of specimen that underwent: (a) continuous heating method in 2 hours, (b) continuous heating method in 6 hours, (c) isothermal heating method in 2 hours, (d) un-post curing.

Fig. 4 shows the surface of specimen fracture. The specimen which underwent treatment using the continuous heating method with 2 hours of heating time failed due to pull-out and fiber fracture as well as shown in (Fig. 4a). However, in majority it was due to fiber fracture. The same phenomenon also occurred in the specimen which underwent treatment using the isothermal heating method with 2 hours of heating time (Fig. $4 \mathbf{b}$ ). Those phenomena showed the good bonding between fiber and matrix. Fiber pull-out was clearly visible in the un-post curing specimen (Fig. 4c). It occurred due to the low bonding strength between the fiber and the matrix. Eventhough the un-post curing specimen had the flexural strength that was nearly as strong as the post-cured with continuous heating one, but the composite was unstable. The un-post curing composite would change in properties when it was exposed to heat. 

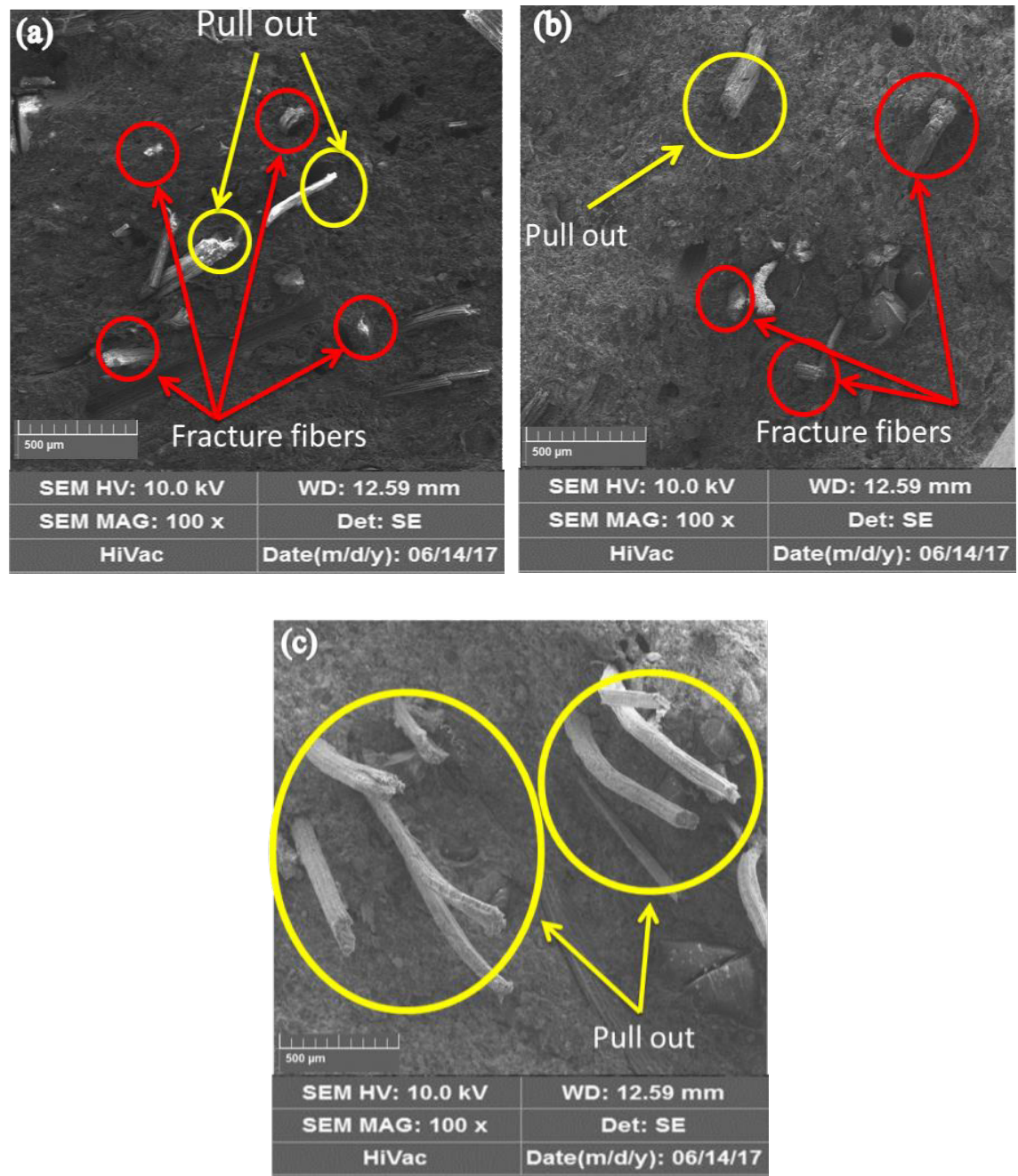

Fig. 4. SEM images of fractures surface of specimen that underwent : (a) continuous heating in 2 hours (b) isothermal heating specimen for 2 hours, (c) un-post curing

\section{Conclusion}

The post curing tended to lower the flexural strength of the specimen if the heating rate was set too fast. The decrease in the flexural strength was caused by the internal defect in the specimen. Formation of internal defect was influenced by the heating rate in post curing. The increase of heating rate induced the formation of larger internal defect. Internal defect was triggered by the release process of ammonia gas during the post curing in the specimen. The flexural strength in the post-cured specimen using the continuous heating method was higher than that using the isothermal heating method. 
The authors gratefully acknowledge the financial support of Ministry of Research, Technology and Higher Education of the Republic of Indonesia through Tim Pascasarjana research grant (contract number: No. 873/UN27.21/PP/2017).

\section{References}

1. U. D. Idris, V. S. Aigbodion, I. J. Abubakar, C. I. Nwoye, J. King Saud Univ. - Eng. Sci., vol. 27, no. 2, pp. 185-192, (2015).

2. K. K. Ikpambese, D. T. Gundu, L. T. Tuleun, J. King Saud Univ. - Eng. Sci., vol. 28, no. 1, pp. 110-118, (2016).

3. J. H. Gweon, B. S. Joo, H. Jang, “Wear, vol. 362-363, pp. 61-67, (2016).

4. C. Menapace, M. Leonardi, G. Perricone, M. Bortolotti, G. Straffelini, S. Gialanella, Mater. Des., vol. 115, pp. 287-298, (2017).

5. E. Surojo, Jamasri, V. Malau, M. N. Ilman, vol. 37, no. March 2016, pp. 473-481, (2015).

6. K. Hirano, M. Asami, React. Funct. Polym., vol. 73, no. 2, pp. 256-269, (2013).

7. H. Ku, F. Cardona, N. Pattarachaiyakoop, M. Trada, J. Compos. Mater., vol. 43, no. 7, pp. 741-754, (2009).

8. A. Izumi, Y. Shudo, T. Nakao, M. Shibayama, Polym. (United Kingdom), vol. 103, pp. 152-162, (2016).

9. B. Theodore, N. M. Ph, plast. Eng. pp. 1-26, (2004).

10. R. M. Rudd, S. R. Ghafarian, A. Taherkhani, vol. 3, pp. 36-39, (2013).

11. W. Stark, H. Goering, U. Michel, H. Bayerl, Polym. Test., vol. 28, no. 6, pp. 561-566, (2009).

12. J. C. Munoz, H. Ku, F. Cardona, D. Rogers, J. Mater. Process. Technol., vol. 202, no. 1-3, pp. 486-492, (2008).

13. S. J. Kim, K. S. Kim, H. Jang, J. Mater. Process. Technol., vol. 136, no. 1-3, pp. 202208, (2003). 